Conclusion Tthe improvement of these indicators is attributed to the improvement the conditions of woman; following, screening and the taken in charge of the high risk pregnancies. As well as the improvment of the taken in charge of the newborns in work-room.

\section{NEWBORN LOW BIRTH WEIGHT: MOROCCAN DATA}

doi:10.1136/archdischild-2012-302724.1304

'A Barkat, ${ }^{2} \mathrm{M}$ Banouar. 'Equipe de Recherche en Santé et Nutrition du Couple Mère

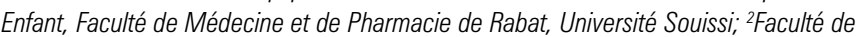
Médecine et de Pharmacie de Rabat; Université Souissi, Rabat, Morocco

Objective The overall objective of this work is to describe the prevalence of newborns with low birth weight in Rabat Souissi Maternity Hospital in 2010. The specific objective is to compare the population of preterm and small for gestational age, assess their immediate future and identify the causes.

Methods The study tok place at Rabat Souissi Maternity Hospital between January 1st 2010 and December 2010. Were enrolled, all newborns weighing $<2500 \mathrm{~g}$. The main variables collected were gestational age, sex, route of extraction, Apgar at $5 \mathrm{~min}$, the maternal age, parity, maternal disease history and immediate future of the newborn.

Results Of 14,808 live births registered during 2010, 1475 newborns had a birth weight less than $2500 \mathrm{~g}$ or $9.96 \%$ of which 722 were small for gestational age, 728 were premature infants. Vaginal delivery was predominant in both populations. The average age of mothers was $(28.22 \pm 6.83$ vs $28.63 \pm 6.60)$ years $(p=0.89)$. The main etiologies encountered were the maternal genitourinary infections for prematurity $(25.6 \%)$ while the main cause of low birth weight were gestational hypertension (11.7). As for becoming immediate mortality was about $11 \%$ in premature infants against $2 \%$ in small for gestational age. $(p<0.001)$. Hospital transfers were in the range of $46.2 \%$. The main indications were respiratory distress, infection, and perinatal asphyxia.

\section{FULL TERM NEONATAL ADMISSIONS IN A REFERRAL HOSPITAL}

doi:10.1136/archdischild-2012-302724.1305

BR Qandalji. Pediatrics, Ministry of Health, Amman, Jordan

Background and Aim Full term neonates represent a significant proportion of neonatal addmisions. The aim of this study was to see the characteristics of this group in the largest neonatal unit in the capital and how these could be reduced to decrease the burden on the neonatal unit.

Patients and Methods All full term neonatal admissions to the nn unit in Al-Bashir h, 1/1/2011-30/6/2011 were included, A special questionnare was filled which included the various characters of the group, sex distribution, birth weight, reason for admission, duration of hospitalisation and outcome.

Results During this period a total of 855 FTNN were admitted representing $47.6 \%$ of total admissions, $80 \%$ were admitted on day one, $60 \%$ were normal vaginal delivery. $90 \%$ were in born, respiratory distress was the main cause of admission, 32\%, IUGR $14.7 \%$, NNJ11.6\%,IODM8\%, ASPHYXIA 7\%,50\% were hospitalised for $1-3$ days, mortality rate was $5 \%, 62 \%$ of which were due to asphyxia, $30 \%$ were due to congenital malformations.

Conclusion FTNN represent a significant proportion of nn admissions the main reason for admission is respiratory distress, and the main reason for mortality is asphyxia, $50 \%$ are hospitalised for 3 or less days. a good nursery with intermediate care would decrease the load on the neonatal unit.

\section{6 PREDUCTAL TRANSCUTANEOUS OXYGEN SATURATION AT} BIRTH AFTER ELECTIVE CAESAREAN SECTION

doi:10.1136/archdischild-2012-302724.1306
'V Dal Cengio, ${ }^{2} \mathrm{M}$ Parotto, ${ }^{1 \mathrm{P}}$ Zanella, ${ }^{1} \mathrm{C}$ Zacchettin, ${ }^{1} \mathrm{~N}$ Rizzo, ${ }^{3} \mathrm{~F}$ Cavallin 'D Trevisanuto, ${ }^{4} \mathrm{~V}$ Zanardo. 'Children and Women's Health Department; ${ }^{2}$ Department of Anesthesia and Pharmacological Sciences, Padua University School of Medicine; 3/ndependent Statistician, Padova; "Neonatology Service, Abano Terme General Hospital, Abano Terme, Italy

Background The 2010 Neonatal Resuscitation Guidelines recommend preductal transcutaneous oxygen saturation $\left(\mathrm{SpO}_{2}\right)$ monitoring at birth in preterm and/or non reactive and/or hypotonic newborns. Previous studies have assessed $\mathrm{SpO}_{2}$ showing that $\mathrm{SpO}_{2}$ immediately after birth is higher in newborns by Vaginal Delivery (VD) vs. Caesarean Section (CS). This difference has never been investigated in newborns by Emergency CS (presence of labour) vs. Elective CS (absence of labour).

Objective To compare $\mathrm{SpO}_{2}$ in newborns by Emergency CS vs. Elective CS in the first minutes of life.

Methods The study included healthy newborns at term by Emergency CS, by Elective CS and by VD as control group. Infants receiving supplemental $\mathrm{O}_{2}$ or assisted ventilation were excluded. $\mathrm{SpO}_{2}$ was recorded for the first 10 minutes of life using a Masimo Radical-7 pulse oximeter probe (Masimo, Irvine, CA) applied to the right hand.

Results We studied 24 newborns by Emergency CS, 57 by Elective $\mathrm{CS}$ and 47 by VD. The $\mathrm{SpO}_{2}$ gradually improved during the first 10 minutes of life in all groups ( $\mathrm{p}$ per trend $<0,0001$ ). The $\mathrm{SpO}_{2}$ were similar in the tenth minute of life in all the 3 groups, but it was always higher in newborns by Emergency CS as well as by VD than in those by Elective CS from minute one to minute nine $(p<0.05)$.

Conclusions $\mathrm{SpO}_{2}$ in newborns by Emergency CS in the first minutes of life is higher than in those born by Elective CS as well as in newborns by VD vs. Elective CS.

\section{HIDDEN TOXICITY IN THE NICU: PHTHALATE EXPOSURE OF VERY LOW BIRTH WEIGHT INFANTS}

doi:10.1136/archdischild-2012-302724.1307

${ }^{1} \mathrm{~A}$ Demirel, ${ }^{1} \mathrm{~A}$ Coban, 'S Yildirim, ${ }^{2} \mathrm{C}$ Ekinci Dogan, ${ }^{2} \mathrm{R}$ Sanci, 'ZE Ince. 'Pediatrics, Division of Neonatology; '2 Istanbul University Istanbul Medical Faculty, Istanbul, Turkey

Aim To determine the exposure of VLBW infants to phthalates during their stay in the neonatal intensive care unit.

Method Preterm infants $(<32 \mathrm{wks}$ and/or $<1500 \mathrm{~g})$, who stayed in the NICU $>2$ wks and had at least one invasive procedure were included. Urine samples were collected in the first 3 days and every 2 weeks until discharge. Phthalate contents of the medical devices, urinary excretion of phthalate metabolites. (diethylhexylphthalate-DEHP, monoethylhexylphthalate-MEHP, monoethyloxohexylphthalate-MEOHP, monoethylhydroxyhexylphthalate-MEHHP) and their relation to exposure intensity, gestational age, birthweight and postnatal age were analysed.

Result Mean gestational age and birth weight of the patients $(\mathrm{n}=36)$ were $28.9 \pm 1.5 \mathrm{wks}$ and $1024 \pm 262 \mathrm{~g}$. DEHP was detected in umbilical catheters, intubation tubes, nasogastric tubes and nasal cannulas. Nasal cannulas had the highest content $(201.7 \mathrm{mg} / 0.5 \mathrm{~g})$. MEHHP was the most frequently detected metabolite $(81.4 \%)$ in the urine samples $(n=151)$ and its levels increased during the first 4 weeks (mean concentration: $319.5 \mathrm{ng} / \mathrm{ml}$ ), were higher in patients who had continuing need of invasive procedures after 2 wks (255.32 $\mathrm{ng} / \mathrm{ml}$ vs $65.85 \mathrm{ng} / \mathrm{ml}$ ), were significantly higher in the first urine samples of patients $<1000 \mathrm{~g}$ compared to those $\geq 1000 \mathrm{~g}(63.17 \pm 93.79$ $\mathrm{ng} / \mathrm{ml}$ vs $10.93 \pm 22.98 \mathrm{ng} / \mathrm{ml}, \mathrm{p}=0.001$ ).

Conclusion Phthalate metabolites could be detected in the urine samples of preterm infants very early after admission to the NICU. The levels were higher in the first weeks of intensive care when exposure intensity was highest and in babies $<1000 \mathrm{~g}$. Monoethylhydroxyhexylphthalate-MEHHP may be the most suitable biomarker of phthalate exposure. 


\section{ASPIRATION OF THE SECRETIONS IN NEONATAL RESUSCITATION. AN EVIDENCE BASED APPROACH}

doi:10.1136/archdischild-2012-302724.1308

Al Toma, I Cuzino, A Cozinov, 0 Raluca. Neonatology, Life Memorial Hospital, Bucharest, Romania

Background and Aims Aspiration of the secretions at birth is a step performed in the care of the newborn immediately after delivery, but it is not supported by evidence-based data. Our study aim is to prove the suction of the secretions is a necessary step in neonatal resuscitation and care at delivery.

Method We studied 1154 consecutive cesarean section deliveries The care at birth was according to the AAP Resuscitation Guidelines, except the neonates were randomized to mandatory aspiration of the secretions at delivery by suction catheter ( $\mathrm{S}$ group) or clearing the secretions from the mouth when they are visible by gentle aspiration of the mouth ( $\mathrm{C}$ group). There were noted the time to first breath, need for bag and mask ventilation, occurrence of respiratory distress, need for mechanical ventilation, blood gas values at delivery.

Results $25 / 577$ of the neonates in the $S$ group developed respiratory grunting after delivery compared with $42 / 577$ neonates in the $\mathrm{C}$ group $(\mathrm{p}<0.001)$. The need of bag and mask ventilation at birth was similar between the groups (10/577 C; 11/577 S group). When stratified for gestational age(GA), 12/253 neonates in the $\mathrm{S}$ group with GA less than 38 weeks presented with respiratory distress and grunting after delivery compared with $35 / 260$ in the $C$ group $(\mathrm{p}<0.001)$.

Conclusions Aspiration of the secretions at birth is a necessary step in the care at birth of the newborns born by cesarean section, especially if they are 38 weeks or less gestational age.

\section{ELEVATED 17-HYDROXYPROGESTERONE [17-0HP] LEVELS: A FETOPLACENTAL MECHANISM TO PREVENT PRETERM BIRTH?}

doi:10.1136/archdischild-2012-302724.1309

'MP Sherman, 'S Younger, ${ }^{1,2 J}$ Sherman. 'Child Health; ${ }^{2}$ Sinclair School of Nursing, University of Missouri - Columbia, Columbia, MO, USA

Background and Aims Elevated 17-Hydroxyprogesterone [17$\mathrm{OHP}$ ] levels in preterm infants are often false positives. We theorized the elevation was related to preterm labor [PTL] and not related to maternal or fetal disease. We surmised that an elevated fetoplacental 17-OHP is akin to obstetrical therapy with progesterone to prevent preterm birth

Methods Infants with congenital adrenal hyperplasia were excluded. Nucleated red blood cell count [nRBC] was a marker of chronic fetal hypoxia or severe preeclampsia and C-reactive protein [CRP] was an indicator of perinatal infection. Using an effect size of 0.5 with a two-tail test, an alpha of 0.05 , and a power of 0.8 , at least 66 infants were needed for this study.

Results Fifty-three male and 47 female infants had a mean gestational age of 32.4 and 31.2 weeks, respectively. No mothers received therapy with progesterone for PTL; however, $84 \%$ of mothers had PTL. Pearson's correlation showed lower birth weight $(r=-0.65$, $\mathrm{p}<0.001)$, gestational age $(\mathrm{r}=-0.64, \mathrm{p}<0.001)$, and one minute APGAR scores $(r=-0.21, p=0.04)$ were significantly associated with increased 17-OHP levels. There was no correlation between CRP or $\mathrm{nRBC}$ and 17-OHP levels. After an initial elevated 17-OHP, repeat testing was normal.

Conclusions Intrapartum infection and preeclampsia did not correlate with elevated 17-OHP levels as previously reported. An elevated 17-OHP in preterm infants is associated with PTL and birth. Whether an elevated 17-OHP level at birth confers protection to preterm infants from morbidity or death requires additional investigation.

\section{A STUDY OF PROFESSIONALS' OPINIONS OF HOME DELIVERIES: A CROSS SECTIONAL STUDY}

doi:10.1136/archdischild-2012-302724.1310

1,2,3T Thornton, ${ }^{4}$ P Clarke, ${ }^{5} \mathrm{DA}$ McNutt, ${ }^{6} \mathrm{~A}$ Curley. ${ }^{1}$ Queen Elizabeth Hospital, Kings Lynn,

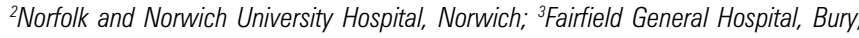
${ }^{4}$ Neonatology Intensive Care Unit, Norfolk and Norwich University Hospital, Norwich ${ }^{5}$ Fairfield General Hospital, Manchester; ${ }^{6}$ Addenbrookes Hospital, Cambridge, UK

Background and Aims A recent Government policy drive is to increase home delivery rates. Data are lacking about whether this strategy is embraced by perinatal healthcare professionals. Our aim was to examine opinions regarding home deliveries held by consultant paediatricians, neonatologists, gynaecologists, obstetricians, GPs and midwives.

Methods Cross-sectional survey of UK professionals in East Anglia. Likert scales ranging from 0-10 assessed professionals' general experiences of and enthusiasm for home birthing and support for the Government's plan.

Results $52 \%$ of professionals responded, including $68 \%$ of Paediatricians. Paediatricians and Neonatologists generally reported negative experiences of home delivery and were considerably less enthusiastic regarding home deliveries than any other professionals.

Paediatricans generally held a negative outlook on home delivery [median 4, IQ 3-5] and were in opposition to the government's plan [median 3, IQ 2-5], whilst midwives were more enthusiastic about home delivery than any other profession [median 9, IO 8-10, $\mathrm{p}<0.0001]$ and were more likely to support the government plan to increase the rate of home deliveries [median 8.5, IQ 7-10, $\mathrm{p}<0.0001$ ]. GP's, obstetricians and gynaecologists tended to give more neutral or negative opinions towards home birth [GP (median 5, IQ 3-7.5) ObGyn (median 5, IQ 2-7)] and towards the government's plan [GP (median 5, IQ 2-6) ObGyn (median 5, IQ 2-5)].

Conclusions Negative experiences and opinions of perinatal healthcare professionals regarding home delivery may adversely affect its uptake by women and will need to be addressed if the Government's plan to increase home delivery rates is to succeed.

\section{1 'TUBES' AND CATHETER POSITIONS IN NEONATES TRANSFERRED TO A TERTIARY NEONATAL INTENSIVE CARE UNIT OVER A 2 YEAR PERIOD}

doi:10.1136/archdischild-2012-302724.1311

'G Nepali, ${ }^{2} \mathrm{M}$ Tasbihi, ${ }^{1} \mathrm{~J}$ Egyepong. ' Neonatal Intensive Care Unit, Luton and Dunstable Hospital NHS Trust; ${ }^{2}$ Department of Paediatric, Luton \& Dunstable University Hospital NHS Trust, Luton, UK

\section{Introduction}

- Endotracheal tubes (ETT), Chest tubes (CT), Nasogastric tubes (NGT), umbilical artery and venous catheters (UAC, UVC), Long lines (LL) are crucial in the management of babies transferred and admitted to neonatal intensive care units (NICU). Optimal positions must be ascertained before transfer and on admission to avoid complications.

- To the best of our knowledge, there has not been any published data looking at admission positions of all these tubes and catheters.

Aim

To determine:

- positions of these tubes and lines on admission of babies transferred for intensive care to a tertiary NICU.

- any radiological and other complications that may have been associated with sub-optimally placement on admission.

Methods

Retrospective study

- 01/2010-12/2011 